
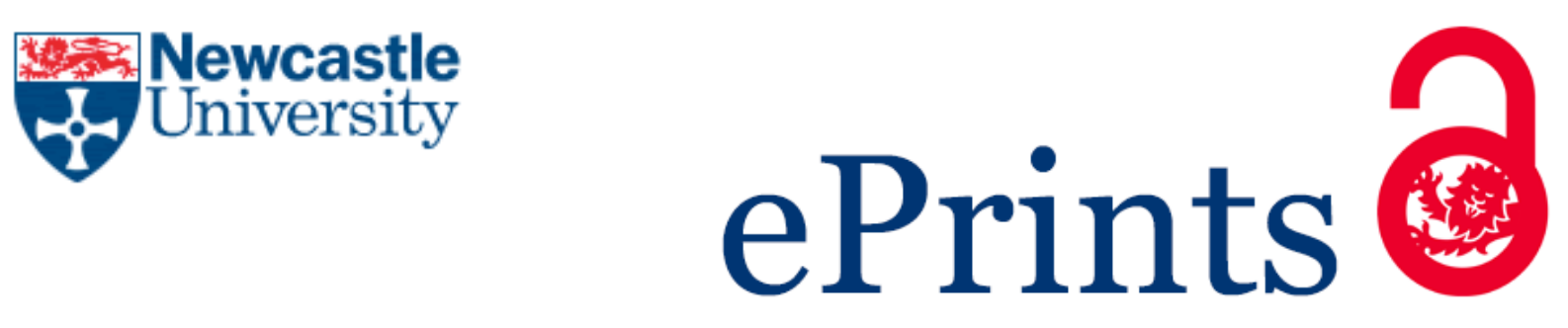

\title{
Elstub S.
}

Democracy in Theory and Practice.

Representation 2010, 46(3), 255-260.

\section{Copyright:}

This is an Accepted Manuscript of an article published by Taylor \& Francis in Representation on 17/09/2010, available online: http://dx.doi.org/10.1080/00344893.2010.499693

Date deposited:

$02 / 03 / 2016$

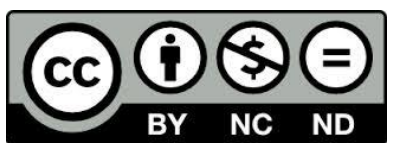

This work is licensed under a

Creative Commons Attribution-NonCommercial-NoDerivatives 4.0 International licence 


\title{
Democracy in Theory and Practice
}

\author{
Stephen Elstub
}

In his classic text on 'democracy' Anthony Arblaster acknowledges that democracy exists in theory and practice. However, for him it is 'a concept before it is a fact' (Arblaster 1994: 3). On the one hand this means that democracy is an 'essentially contested concept' (Gallie 19955-6), but on the other it also means it is a normative and critical concept 'by which reality is tested and undertaken' (Arblaster 1994: 8). Arblaster, however, continues: 'This is not to say that a perfect democracy is in the end attainable...it is rather the idea and ideal is always likely to function as a corrective, rather than as a prop, to complacency' (Arblaster 1994: 8). Arblaster therefore gives us an important insight into the complex relationships that exists between theory and practice in relation to democracy. In one sense democracy exists in practice and we must seek to explain how and why it operates as it does, and theorise accordingly about what is practically possible in a given context. On the other it is a normative ideal that can and should criticise and guide practice. Consequently, a critical distance from practical reality is clearly required. However, if practical reality is ignored then the ability of theory to inform democratic practice in context is clearly compromised. There is then a complex and symbiotic relationship between democratic theory and practice, and the purpose of this special edition is to reflect upon this relationship further, to gain a deeper understanding of the nature of the relationship. All six papers in this special edition therefore confront the relationship between democracy in theory and practice, by focusing on institutionalisation of democracy, but do so in a number of different ways. Firstly they consider different, but related, democratic principles and concepts: legitimacy (Bader), political equality (O'Flynn), deliberation (Chappell, and Elstub) and participation (Blakeley and Evans, and Mahony). It is clear to see from these papers that the theoretical principle of democracy being considered effects the relationship to practice. A range of practical contexts are also considered: multi-level polities (Bader), deeply divided societies (O'Flynn), whole polities (Chappell), local areas, both rural (Elstub) and urban (Blakeley and Evans), and range of spectacular events (Mahony). It is apparent the nature of the context influences the relationship with theory too. As well as briefly outlining the content of these papers, as indicated in the discussion above, this introduction encourages us to take an approach to democracy that combines normative theory and empirical enquiry, while not conflating the two approaches altogether. It therefore echoes Beetham's sentiment that we must move beyond 'the separation of institutional accounts of democracy from any analysis of democracy's underlying principles' (Beetham 1999: 29). We see such an approach adopted by the contributors here in the special issue, but in a number of different ways.

The argument here is that the current divide between democratic theory and practice is a false, unnecessary separation that hinders our understanding of democracy (Rothstein 2005: 10). An excessive detachment between theory and practice manifestly hinders the advancement of the study of democracy and is now a 'fundamental obstacle' to progress in the discipline (Fung 2007: 443). As Shapiro (2003: 2) explains: 'speculation about what ought to be is likely to be more useful when informed by relevant knowledge of what is feasible, and partly because explanatory theory too easily becomes banal and method-driven 
when isolated from the pressing normative concerns that have fuelled worldwide interest in democracy.' In fact this dichotomy doesn't just affect the study of democracy, but needs to be overcome in political science per se: 'Adequate social and political theory must be empirical, interpretive, and critical' (Bernstein 1979: 235).

For Rothstein empirical science requires normative and moral ideas otherwise we end up with 'technically competent barbarians' (Rothstein 2005: 10). Dryzek (2007) and Thompson (2008) both argue that although there are many claims imbedded in democratic theory that can and must be empirically tested in practice, there are normative claims to legitimacy that cannot be. Therefore empirical studies of democracy are hindered by an absence of explicitly normative concepts, and empiricists are naive to presume that it is possible to study democracy in a manner free of normative assumptions (Gerring and Yesnowtiz 2006). This is because empirical inquiries have 'normative implications', and are often not neutral and scientific 'since they justify- in an ideological and specifically conservative spirit- the existing workings of the political system they have described' (Skinner 1973: 288). The danger is that political scientists, when researching democratic practice uncritically accept the processes of the current system and potentially come perilously close to being 'apologists for the existing political order' (Walker, cited in Skinner 1973: 288). We therefore require the critical edge of normative theory: 'Theory challenges political reality. It is not supposed to accept as given the reality that political science purports to describe and explain. It is intended to be critical, not acquiescent' (Thompson 2008: 499). Therefore, one should not accept political reality as a reified given, and essentialise the contextual features and the political procedures currently in place. Rather empirical theory must keep sight of the normative goals of democratic theory, and strive to improve practice, accordingly, where possible.

Normative theory certainly is critical of practice, and assumes reality does not have to be like that, but this does not mean that it necessarily is, or that it should be, 'an evidence-free zone' (Dryzek 2007: 237). Without empirical political science we will be unaware of the conditions that democracy can operate effectively in, and the tensions that exist between key elements of democracy. Moreover, empirical evidence is also required to ensure the critical edge of theory is realistic and practically grounded, as it informs us which unfavourable features of current democratic practice can be changed (Thompson 2008: 500). Consequently, empirical evidence on democracy gives us 'a sense of what may work, how, when, and whyand what may be difficult' (Dryzek 2007: 240). Such evidence must be taken seriously by normative democratic theorists if the theories are to actually influence practice.

However, empirical evidence can tell us the tensions that exist in democracy in practice, but the answers to how trade-offs should be made between these concepts ultimately needs to be determined by normative theory. For this reason democratic theory still has 'the upper hand' (Thompson 2008: 513). Steiner et al (2004: 42), empiricists themselves, are also cautious about the role empirical research can play. Although they argue it is vital, they ultimately accept Habermas's contention that it can only provide a 'helping hand' to normative democratic theory (Habermas 2006). Chambers (2003: 320) concurs that empirical research on democracy is essential in debates about institutionalisation and achieving 
democracy in practice. However, similarly she argues that empirical research 'cannot be the last or leading word.' For this reason theory and practice must be connected, but still remain distinct.

Thompson (2008: 499) indentifies three elements required for complete analysis of deliberative democracy, but they are equally relevant to democratic analysis more generally. They include conceptual criteria, evaluative standards, and empirical conditions. All three require theoretical understanding, but can also be subject to empirical enquiry. Conceptual criteria establish what can be classified as democracy; evaluative standards indicate what the superior forms of democracy are; while empirical conditions inform us about the requirements that are necessary to achieve the conceptual criteria and evaluative standards. The papers in the special issue primarily focus on the empirical conditions, but also employ an understanding of practice to reflect upon, and theoretically engage with, the relevant conceptual criteria and evaluative standards of democratic theory.

The first attempt to combine democracy in theory and practice here is provided by Veit Bader in 'Complex Legitimacy in Compound Polities: The EU as Example.' Bader attempts to assess the problem of legitimacy in compound polities, using the European Union as an example. He argues that the practice of multi-level governance, transnational, and, in fact, all compound polities requires the theory of democratic legitimacy, from its traditional basis of consent, to be modified. This is because determining who the relevant groups are that need to consent becomes increasingly complex. Basing this on nation states is simply inadequate. Bader therefore argues that we need a much more refined and complex understanding of legitimacy that involves making trade-offs, in theory and practice between constitutional, democratic, and output legitimacy. In reconfiguring a theory of legitimacy, that is suitable for compound polities, Bader takes much inspiration from institutional pluralism to suggest trade-offs that need to be made between the problems of legitimacy that are inherent in multi-level polities and the problems arising from new forms of multi-level governance. Ultimately he wants multi-level polities like the EU to be more transparent, open and inclusive, easier to control, and more representative and politically legitimate, but this requires trade-offs with practical exigencies to achieve effectiveness and efficiency. Bader's article is then a serious and important attempt to reconcile normative theory and practice.

In 'Democratic Theory and Practice in Deeply Divided Societies', Ian O'Flynn shares the perspective, asserted here, that empirical enquiries into practice raise normative questions. He applies normative theory to consider the potential democratic arrangements have to deal with ethnic disputes in deeply divided societies. O'Flynn praises the excellent empirical research that has been provided on this issue, believing normative theory must pay serious attention to this to ensure their proposals are feasible. However, he emphatically asserts the need for normative theory to provide guidance on the larger goals divided societies should aim to pursue. In particular O'Flynn considers the normative democratic value of political equality, demonstrating how this principle can guide the members of a deeply divided society to respond to the demand of institutional accommodation made by some ethnic groups, as well as the need for more extensive political integration. He argues that a proper 
understanding of political equality means that we should take a 'self' rather than a 'pre' determination approach to including ethnic groups. This means democracies should only accommodate ethnic groups once they have spontaneously emerged. To highlight these debates he focuses on electoral systems in divided societies, and argues that the single transferable vote system most appropriately complies with the normative standards of political equality, an approach to 'self-determination', and the available empirical evidence from deeply divided societies. O'Flynn's paper then clearly addresses the complex relationship between democracy in theory and practice head on, clearly demonstrating the importance of normative theory.

Zsuzsanna Chappell, in 'A Tension Between Ideal and Practice: Re-evaluation of Micro and Macro Models of Deliberation', reflects upon the constraints practice provides to the instutionalisation of a particularly deliberative conception of democracy. She examines idealised normative deliberative theory by drawing on the distinction between a micro instutional approach (formalised debates) and a macro instituional approach (disaggregated public debate). Chappell argues that the micro appraoch cannot institutionalise deliberative democracy, but the macro approach does not resemble the ideal theory of deliberative democracy very closely at all, and fails to preserve the apsects that makes deliberative democracy normatively distinct in the first place. Effectivley it becomes hard to distinguish from liberal representative democracy. For Chappell integrating the micro and macro would still lead to a dominance of the macro, and so would not solve the problem. Chappel's contribution therefore provides us with important lessons about the relationship between ideal normative theory and its applicability to practice, ultimately concluding that trade-offs need to be made between the two, but also warning the deliberative theory might not 'present us with an alternative empirical reality of organising democratic politics.' Distinguishing excessively between normative theory and practice in relation to democracy, is then, for Chappell, not particularly helpful. Her article therefore highlights the limitations of excessively idealised normative theory.

Stephen Elstub, in 'Linking Micro Deliberative Democracy and Decision-Making: Trade-Offs Between Theory and Practice in a Partisan Citizen Forum', also focuses on deliberative democracy, and also focuses on the distinction between micro and macro approaches to institutionalising deliberative democracy. In contrast to Chappell's paper though, Elstub considers a case study, from the Peak District in the UK, of a micro instance of deliberative democracy. Specifically he classifies it as a partisan citizen forum, but he argues that partisan deliberation can also be classed as micro deliberation. Such a case study therefore makes a start of re-addressing the balance of all the research that has been conducted on randomly sampled, unpartisan, mini-publics in relation to deliberative democracy. He attempts to learn about the trade-offs that are made between ideal deliberative theory and practice in partisan micro forums, specifically in relation to linking deliberation with decision-making, at different stages of the decision-making process. Elstub takes a deductive approach, employing Habermas's ideal speech situation as a heuristic to examine practice. 
In his recent, but influential article, Saward (2003) encourages us to take a different approach to the relationship between democratic theory and practice, which has had a considerable influence on the last two articles in this special edition. Saward wants the study of democracy to 'forge certain links between ideals and practical mechanisms'. However, he argues that we should adopt an 'ecumenical' approach to democracy rather than focusing on a particular model or theory such as deliberative democracy, as Chappell and Elstub do here. The thrust of Saward's argument is that all democratic principles and institutions contain varying 'bundles' of interpretations, but it is institutions and devices that enact these interpretations. Saward terms such an approach 'reflexive proceduralism'. Tracing the links between the principles, cannot be a purely abstract process: 'indeed it is fundamental to reflexive proceduralism that principles gain much of their recommendatory force and specific meaning from successes and stresses in the operation of the devices (mechanisms, institutions, practices) which enact them' (Saward, 2003, p. 164). He therefore suggests that we take an inductive approach to democratic institutions. We should focus much more on practice and context, and see what combinations of democratic principles are actually being enacted.

In 'Citizen Participation in East Manchester: From Practice to Theory', Georgina Blakeley and Brendan Evans take such an inductive approach. They focus on a case study of citizen participation in an urban regeneration programme in East Manchester, in the UK, and use this practice to reflect upon democratic theory. Blakeley and Evans find Saward's reflexive approach particularly useful when evaluating citizen involvement as it is much more sensitive to crucial determinants of participation, and the affects that it can achieve on decision-making, like temporality, spatiality and complexity, than deductive approaches to democracy. These proved to be vital variables in relation to citizen participation in their case study. For Blakeley and Evans then we should not start with normative theory and analyse practice to see how closely it lives up to the theory, but start with practice and let theory emerge from political reality.

Nick Mahony, in 'Making Democracy Spectacular', also takes an inductive approach to democracy in theory and practice, and is similarly influenced by Saward's reflexive proceduralism. He focuses on three examples from the UK of what he sees as a proliferation of spectacular democratic events. The events themselves are drawn from the diverse fields of government, popular media and social movements, but all try and engage citizens in different ways. Mahony reviews them so that we can learn to what extent making such events 'spectacular' facilitates or detracts from the enactment of democratic renewal. He concludes that spectacularisation can prove engaging, but also demanding for citizens. In doing this Mahony deliberately refrains from offering any preferred normative conception of democracy. He argues that democratic concepts are indeterminate and decontested in practice, so we should learn from practice the nature of this decontestation in specific contexts. This approach is reinforced by his case studies which all 'enacted a form of democratic politics by publicly challenging various aspects of different pre-existing democratic forms', but could not be associated with any particular normative 'model' of democracy. 
The limitations of an inductive approach for Fung is that it is 'difficult to connect these inductive projects to broader conceptions of democracy that are intended to apply across a wide range of problems, circumstances, scales, and times' (Fung 2007: 445). Furthermore, the problem of how to know when we have, or have not, reached an appropriate balance between democracy in theory and practice, is still present. In attempting to resolve these two issues Fung offers an approach he terms 'pragmatic equilibrium.' A theory of democracy is in pragmatic equilibrium if 'the consequences of the institutions that it prescribes realize its values well and better than any other feasible institutional arrangements over a wide range of problems and contexts' (Fung 2007: 445). Effectively all approaches to democracy have values that should be produced by the recommended institutions, and if the democratic values and institutional consequences are consistent then pragmatic equilibrium is achieved. When a theory of democracy is unable to meet these requirements practical reasoning on the relationship between institutions and democratic values should be invoked to modify the theory of democracy so that it does get closer to pragmatic equilibrium. Fung's approach has much promise for a fruitful way of combining democracy in theory and practice, and its Dewian pragmatism should be applauded. Nevertheless, there is concern about the place of normative theory here. One of the key problems for more 'radically' normative interpretations of democracy, is that there are often few, or no, actual institutions and practices occurring in the real world that resemble or approximate the normative interpretation of democracy that can be empirically investigated (Parkinson 2006: 8). By pursuing the practical equilibrium approach excessive credence could be given to current democratic mechanisms and processes, and blunting democratic imagination.

We need to ensure that there is not a 'rigid divide' between democratic theory and practice, while ensuring that they remain distinct. Theorists should therefore engage in empirical research of democratic practice, and empirical scientists should reflect upon and engage with democratic theory. If such a relationship is achieved neither discipline would be 'lending a helping hand', or have 'the upper hand', but rather could 'progress hand in hand' (Thompson 2008: 516). This special issue demonstrates a variety, but not exhaustive number of ways this can be achieved.

\section{REFERENCES}

Arblaster, Anthony. 1994. Democracy. Buckingham: Open University Press.

Beetham, David. 1999. Democracy and Human Rights. Cambridge: Polity.

Bernstein, Richard J. 1979. The Restructuring of Social and Political Theory. London: Methuen.

Chambers, Simone. 2003. Deliberative Democratic Theory. Annual Review of Political Science 6: 307-26. 
Dryzek, John. 2007. Theory, Evidence, and the Tasks of Deliberation. In Shawn W. Rosenberg (ed.), Deliberation, Participation and Democracy: can the People Govern? Basingstoke: Palgrave, pp. 237-50.

Dryzek, John. 2008. The Empirical Turn in Deliberative Democracy. Paper presented at the Theory and Practice of Deliberative Democracy Workshop. Canberra: Australian National University.

Fung, Archon. 2007. Democratic Theory and Political Science: A Pragmatic Method of Constructive Engagement. American Political Science Review 101: 443-58.

Gallie, William B. 1955-6. Essentially Contested Concepts. Proceedings of the Aristotelian Society 56: 167-98.

Gerring, J. And Yesnowitz, J. 2006. A Normative Turn in Political Science? Polity 38: 10133.

Habermas, Jürgen. 2006. Does Democracy Still Enjoy an Epistemic Dimension? The Impact of Normative Theory on Empirical Research. Communicative Theory 16: 411-26.

Parkinson, John. 2006. Deliberating in the Real World: Problems of Legitimacy in Deliberative Democracy. Oxford: Oxford University Press.

Rothstein, Bo. 2005. Is Political Science Producing Technically Competent Barbarians? European Political Science 4: 3-13.

Saward, Michael. 2003. Enacting Democracy. Political Studies 51: 161-79.

Shapiro, Ian. 2003. The State of Democratic Theory. Princeton: Princeton University Press.

Skinner, Quentin. 1973. The Empirical Theorists of Democracy and their Vritics: A Plague on Both Their Houses. Political Theory 1: 287-306.

Steiner, Jürg, Bächtiger, Andre, Spörndli, M. And Steenbergen, M. R. 2004. Deliberative Politics in Action: Analysing Parliamentary Discourse. Cambridge: Cambridge University Press.

Thompson, Dennis. 2008. Deliberative Democratic Theory and Empirical Political Science. Annual Review of Political Science 11: 497-520. 